\title{
Developing reflective competence of university students through network volunteering
}

\author{
Tatiana Usheva $^{1}$, Irina Fedosova $^{1 *}$, Oksana Tirskaya $^{2}$, Elena Kazankova $^{2}$, and Svetlana \\ Byvaltseva $^{2}$ \\ ${ }^{1}$ Irkutsk State University, 664003, Irkutsk, Russia \\ ${ }^{2}$ Irkutsk State Medical University of the Ministry of Health of the Russian Federation, 664003, \\ Irkutsk, Russia
}

\begin{abstract}
The article describes the facilities of volunteering for students in social pedagogy and medicine during their professional training. Theoretical and methodological basis for developing students' reflective competence, facilities for modeling it and implementing it at university through volunteering are considered. Successful development of reflective competence of students is viewed through volunteering and based on mastering the ways of social and professional behavior and new social roles. It is implemented in uneven-aged groups and depends on conscious choice of contents, forms, methods and means of training at university. That is what constitutes the concept of the research. The aim of the study is to develop, substantiate and implement theoretical and conceptual grounds for developing reflective competence of students in pedagogy and medicine at university through volunteering. The research experimentally proved the important role of volunteering in developing reflective competence of future specialists at university. It showed the correlation of characteristics of educational space at university and facilities for transferring effective reflective practices to volunteering. The results of the research indicate that developing reflective competence of future specialists through volunteering is a long process which should be specially organized. The aim of improving student's reflective competence is personal and professional selfdevelopment. Based on the studied scientific literature, the authors revealed the characteristics of volunteering as a social and pedagogical phenomenon which had a positive influence on social and professional development of students.
\end{abstract}

\section{Introduction}

In the modern professional sphere, a pedagogue should be able to refer to his or her own inner world and understand the motives of his or her own behavior.

The process of self-discovery and analyzing oneself as a subject of professional activity is only possible if the subject has fully formed reflective competence. Speaking of introducing the concept of competence, we should first answer the question: what is competence? In the interpretation of the concept of competence, an extremely important

\footnotetext{
*Corresponding author: itf76@mail.ru
} 
element is transferring of knowledge and skills of students to practice [1].

Transition to the new system of higher education levels increases the level of freedom in educational choices of students. Now they have a right and obligation to build a personal route of training and professional development. According to T.G. Ozernikova and N.E. Strogova, educational programs are now oriented to student's capabilities and the social meaning of such programs is to develop personal potential of students, their ability to set activity goals and find methods of achieving these goals on their own [2, 3].

The field of our research is volunteering for developing reflective competence of future specialists at university.

Modern volunteering can be viewed as an area of social and professional tests (A.V. Kibalnik) [4]. While volunteering, young people master the ways of social and professional behavior, new social roles as well as social and professional kinds of activity. Y.V. Senko and M.N. Frolovskaya describe their experience of work at university. They conclude that different situations make a person manifest particular features and abilities. A person has an opportunity to show his or her worth, assess oneself and the results of his or her own work $[5,6]$.

Helping other people and solving their problems allows a volunteer to mediately solve his or her own problems which means that volunteering is important for both volunteers and people who need their help. Doing socially significant work in his or her free time, a volunteer receives some new knowledge, expands his or her experience, develops communicative culture, and feels his or her importance. This experience can later become a positive factor in social career and professional growth.

Volunteering in 2020 for the students of medical and pedagogical universities of Irkutsk became an opportunity to help people in need as well as an impetus to ponder on their professional destination and choice based on reflection.

The pandemic caused by COVID-19 caused a change in forms and methods of teaching, cardinal transformation of training formats, transition to innovative technologies in education, and updated volunteering. Higher education turned to volunteering as one of social and educational technologies. Theoretic classes for volunteers were organized in ZOOM and Moodle. These platforms served as the basis for network training of volunteers. Network education is a relatively new technology in education based on the idea of mass collaboration, ideology of open educational resources combined with network interaction of participants [6].

The aim of the article is to describe the results of the research on the influence of volunteering on developing student's reflective competence.

\section{Materials and methods}

The aim of the empirical stage of the research was to experimentally prove our hypothesis and its provisions that successful development of reflective competence is conditioned by the level of reflective skills. Their forming takes place during volunteering which allows students to master the ways of social and professional behavior, new social roles which are carried out in uneven-aged groups and with conscious choice of contents, forms, methods and means of training at university.

In March, 2020 the Pedagogical Institute of the Irkutsk State University established a volunteering team. It is a voluntary consolidated association of students from two universities (the Irkutsk State University and the Irkutsk State Medical University) involved in socially significant activity for helping people in need.

First, for achieving the aim of experimental research we conducted a stating experiment for estimating the level of reflective skills of students. We used the following methods: the questionnaire of estimating individual level of reflectivity manifestation (A.V. Karpov), the 
method of estimating the ability to understand oneself and others in the communication process (an adaptive version of Q-sort technique), the method of studying reflective analysis (S.D. Neverovich, N.V. Samoukina, E.N. Kuchumova), and the method of studying cooperative reflection (T.F. Usheva, E.A. Ponomareva, E.V. Paravyan) $[7,8,9,10]$.

The diagnosing included the students of two universities: the Irkutsk State University and the Irkutsk State Medical University. Procedures and methods of research were carried out in mixed groups of bachelor students in psychological and pedagogical education and on specialist degree students in dentistry aged from 17 to 23 . The research included the analysis of diagnosing materials of 62 students from control and experimental groups.

The method of estimating individual level of reflectivity manifestation of A.V. Karpov is a questionnaire including 27 positions [7]. The response options differ in the level of reflectivity manifestation, the importance of behavior details, and details of predictable results. The results received from this method indicate the development of reflective abilities which define the level of reflectivity.

The ability to understand oneself and others in the communication process was estimated by means of Q-sort technique - an adaptive version suggested by A.V. Batarshev. Students were offered a set of cards with statements or personality traits. They had to be sorted to groups from the most characteristic to the least characteristic for the students. It was extremely important to our study that, due to this method, students manifested their individuality, their real ideas of their abilities and not the compliance with statistic norms and other people's results [8].

For the purpose of defining the level of development of intellectual reflection, we modified the method of studying reflective analysis for chess players elaborated by S.D. Neverovich, N.V. Samoukina, and E.N. Kuchumova. This method was based on the concept of developmental training and understanding the mechanism of forming student's reflection (V.I. Slobodchikov, G.A. Tsukerman, A.Z. Zak, L.V. Shkerina). Reflection is a mental action of realizing the basics of one's own thinking. The skill of correct position assessment is one of important indices. Volunteering is just the same: the skill of correct position assessment allows future specialists to react swiftly in various situations while volunteering [11].

For studying cooperate reflective skills, there was developed a special method (T.F. Usheva, E.A. Ponomareva, E.V. Paravyan) including a group stage and an individual stage. The method was based on the activity approach: the research participants did reflections after their activities. The results of this inner self-observation were compared with the results of external observation and were analyzed. Thus, we made a conclusion about the level of skills of self-determination, following a collective task, taking responsibility for what happens in one's group, organizing one's own activity step by step, and comparing results of activity with its purpose.

Such a complex approach to studying reflective competence finds confirmation in the works of foreign researchers such as Meierdirk C., Nam J., O’Neill T.A. [12, 13, 14].

Complex diagnosing was aimed at studying the level of the following reflective skills:

personal skills: the ability to analyze oneself, adequate self-perception, the ability to find and analyze the reasons of one's own behavior, its results and mistakes, understanding of one's qualities in the present compared to the past and predicting the prospects of developing these qualities;

communicative skills: the ability to put oneself in other person's position, understanding the reasons of other person's behavior during interaction, analyzing the previous situations and taking into account other people's actions while building one's behavioral strategies;

intellectual skills: defining the basics of one's own activity, assessment of one's position, the ability to predict the further actions, the ability to go back and estimate if the chosen plan was correct; 
cooperative skills: self-determination in a work situation, the ability to follow a collective task, taking responsibility for what happens in one's group, the ability to organize one's own activity step by step and compare results of activity with its purpose.

\section{Results}

The method of reflection studying demanded a comparison of indices: self-determination in a work situation, the ability to follow a collective task, to take responsibility for what happens in one's group, to organize one's own activity step by step and compare results of activity with its purpose. We compared the indices of control and experimental groups at the beginning of the experiment (March, 2020) and at the end of it (December, 2020). The comparison was conducted with the use of Spearman's rank correlation coefficient. The comparison data is presented in the Table 1.

Table 1. Comparison of research results of the experimental and control groups (uneven-aged mixed groups).

\begin{tabular}{|c|c|c|c|c|}
\hline \multirow{2}{*}{ Index } & \multicolumn{2}{|c|}{ Experimental group } & \multicolumn{2}{c|}{ Control group } \\
\cline { 2 - 5 } & March, 2020 & $\begin{array}{c}\text { December, } \\
\mathbf{2 0 2 0}\end{array}$ & March, 2020 & $\begin{array}{c}\text { December, } \\
\mathbf{2 0 2 0}\end{array}$ \\
\hline Self-determination & -0.348 & 0.717 & -0.352 & -0.123 \\
\hline Collective task & -0.059 & 0.671 & -0.056 & 0.309 \\
\hline Responsibility & -0.080 & 0.653 & -0.090 & 0.242 \\
\hline Step-by-step organizing & 0.174 & 0.786 & 0.180 & 0.352 \\
\hline $\begin{array}{c}\text { Comparison of results and } \\
\text { purpose }\end{array}$ & 0.539 & 0.867 & 0.521 & 0.048 \\
\hline Total index & -0.178 & 0.878 & -0.180 & 0.180 \\
\hline
\end{tabular}

A decrease of indices of the experimental group in the first months of volunteering can be explained by the very mechanism of reflection. It launches when a person faces difficulties. On the first stage of the experiment, the students of the experimental group had problems with self-determination, could not define the goals of their activity, formulate and describe its results. The process of problematization compelled the experimental group students to realize their learning incompetence on the first stage of the experiment and their professional incompetence on the second stage of the experiment. However, conscious withdrawal from problematization allowed the students to use their skills of self-examination and situation analysis including the understanding of situation participants' positions, purpose analysis, comparing purposes to results, step-by-step activity and taking responsibility for their own actions.

Creating conditions for reflection is one of the essential characteristics of support. Reflection support in education is the expression of the following ideas which can also be pedagogic conditions: subjectivity in educational process, individualization, dialogueness and metasubjectivity. The students' actions of self-examination, analysis of subjects and situations are compact.

The idea of subjectivity in education suggests student's activity. Students can always ask themselves: "Why am I doing this?" and answer this question. During students' selfexamination and assessment of their own activity, they can ask themselves questions such as "What am I like as a student?", "What are my personal qualities?", "Do my actions in this situation meet my principles?", "What are my purposes?", "What is the motivation behind my activity?", etc. In our opinion, questions like this describe students' reflective attitude to themselves as subjets of volunteering. 


\section{Discussion}

Based on the analysis of every kind of reflective skills, we can see a system in their forming: personal and communicative skills are basic, while intellectual and cooperative skills are formed from the basic ones.

In the process of volunteering, students master reflective skills under specially created pedagogic conditions. They learn to make decisions and predict their consequences, to analyze their own activity (its progress and intermediate results), master positioning and selfdetermination in difficult situations, and learn the methods of communication in group. According to I.I. Barkhovich and M.I. Shilova, all of this prepares students for professional communication [15].

The expected result is upgrading students' competences to a new level of development. It becomes possible due to students' realization, understanding and qualitative assessment of the ways and methods of activity existing in the modern society.

\section{Conclusion}

Various forms of interaction of volunteer students with people in difficult life situations allowed the students to gain social experience, some professional skills and knowledge, get personal contacts, and establish a reputation of qualified specialists with the required reflective competences.

In conclusion, participation of students in volunteering helps their self-fulfilment and the forming of reflective competence. Volunteering of future teachers and doctors is viewed as one of the ways of their personal and professional development.

\section{References}

1. V.A. Adolf, S.N. Moskvin, Krasnoyarsk State Pedagogical University Bulletin. 1(51), 37-47 (2020)

2. T.G. Ozernikova, Proceedings of the Irkutsk State Economic Academy 25(2), 196-205 (2015)

3. N.E. Strogova, The World of Science, Culture and Education 1(68), 187-189 (2018)

4. A.V. Kibalnik, South Ural State University Bulletin. Education. Pedagogy Series 8(1), 74-79 (2016)

5. Y.V. Senko, Pedagogy 8, 52-58 (2010)

6. M.N. Frolovskaya, Humanist basics of teacher's professional culture (A monograph, Altai State University Publishing, Barnaul, 2011)

7. T.F. Usheva, T.A. Zhdanko, A.G. Shumovskaya, The European Proceedings of Social and Behavioural Sciences 1143-1149 (2020). doi: 10.15405/epsbs.2020.10.05.151

8. T.F. Usheva, South Ural State University Bulletin. Education. Pedagogy Series 9(1), 4251 (2017) doi: 10.14529 / ped170106.

9. L.V. Shkerina, Methodology of diagnosing and assessing the level of professional competences of future mathematics teachers (Krasnoyarsk State Pedagogical University, Krasnoyarsk, 2015)

10. I.V. Fedosova, T.F. Usheva, I.V. Berinskaya, A.V. Kibalnik, O.V. Gordina, Man in India 97(15), 539-558 (2017)

11. I.I. Barakhovich, M.I. Shilova, Krasnoyarsk State Pedagogical University Bulletin 2(28), 37-40 (2014) 
12. C. Meierdirk, Reflective Practice 18(1), 23-41 (2017)

13. J. Nam, Reflective Practice 18(1), 123-132 (2017)

14. T.A. O’Neill, et al., Academy of Management Learning \& Education 16(2), 257-276 (2017)

15. L.V. Shkerina, V.A. Shershneva, V.N. Sidorov, T.V. Sidorova, K.V. Safonov, European Journal of Contemporary Education 17(3), 357-367 (2016) 